\title{
LXVIII. Observations on urinary calculi, with a descriptive account of the collection in the museum of St. Bartholomew's Hospital
}

Thomas Taylor Esq. M.R.C.S.

To cite this article: Thomas Taylor Esq. M.R.C.S. (1838) LXVIII. Observations on urinary calculi, with a descriptive account of the collection in the museum of St. Bartholomew's Hospital , Philosophical Magazine Series 3, 12:76, 412-420, DOI: 10.1080/14786443808649477

To link to this article: http://dx.doi.org/10.1080/14786443808649477

曲 Published online: 01 Jun 2009.

Submit your article to this journal $[\pi$

Џll Article views: 2

Q View related articles $\sqsubset$ 


\section{Mr. T. Taylor's Observations on Urinary Calculi}

and Petit into the specific heats of metals, observes that they have rendered it extremely probable that the atoms or equivalents of these elementary bodies have the same specific heat; and that the usually received atomic weights of silver, gold, and mercury should be halved. The table in which this comparison is exhibited contains sulphur and 13 metals; and with respect to it the late Dr. Turner remarks, "It will be observed on inspecting the last column of the table, that the product of the specific heat into the atomic weight is very nearly 3 for the first eight substances. Platinum deviates visibly from the law, and bismuth and cobalt strikingly. The three last metals (mercury, silver and gold) would nearly coincide with the law, were their respective atomic weight estimated at half the number given in the table." Waiving the objections which Dr. Dalton has made to the results of these experiments, it is, I think, requiring too much to ask chemists to reduce the atomic weights of three metals to one half, when of 3 others one deviates visibly and two strikingly from the law.

The difficulty with respect to mercury, gold, and silver may, however, I think, be got over in a way which I wonder did not suggest itself to Professor Johnston. If heat combines with bodies in definite proportions, it may in some cases like other elements combine in double proportions; instead therefore of halving the equivalents of these metals, let us suppose that they are combined with two equivalents of heat, and the revolution of atoms with which we are threatened will be rescued from this source of discrepancy.

It is an old observation that when things get to the worst they will mend; I hope therefore that two more Professors may attempt to remove the difficulties of isomorphism, one by multiplying the received atomic weights by 19 , or any equally convenient number, and the other by dividing them by the same.

LXVIII. Observations on Urinary Calculi, with a Descriptive Account of the Collection in the Museum of St. Bartholomere's Hospital. By Thomas Taylon, Esq., M.R.C.S.

To the Editors of the Philosophical Magazine and Journal. Gentlemen,

HAVING completed the examination of the valuable collection of urinary calculi, of which the specimens of cystic oxide described in your April Number, p. 337, form a part, may I request the insertion of the following observations, should you deem them of sufficient interest to merit a place 
in your pages? The entire collection consists of 129 specimens, of which about one third were unexamined; the composition of the others had been pointed out some few years ago by Dr. Hue. It was however necessary to re-examine many of these, as from their not having been divided their internal structure had not been described. In this as in most other collections chemical composition has been taken as the basis of arrangement. This plan would be sufficiently simple and accurate if calculi were always homogeneous, but as by far the greater number consist of layers differing in composition, some additional method is necessary. In the present instance the alternating calculi have been classed according to the number of layers which are present, and these are subdivided with reference to the composition of the nucleus. I am aware that many objections might be urged against this method, and it would no doubt have been more scientific to have grouped together all those in which the layers observe a similar order of succession; but it was found that such an arrangement would have introduced so many subdivisions as completely to destroy that simplicity which in a museum continually subject to increase it was necessary to preserve.

The following table exhibits the relative frequency of each species, together with the order of succession of the layers in the alternating calculi.

$\begin{array}{llllllll}\text { Uric acid, nearly pure } & \ldots & \ldots & \ldots & \ldots & \ldots & \ldots & 11 .\end{array}$ $\left.\begin{array}{c}\text { Urate of ammonia intimately mixed with variable } \\ \text { proportions of oxalate of lime and the phosphates }\end{array}\right\} 8$.

$\begin{array}{llllll}\text { Oxalate of lime nearly pure } & \ldots & \ldots & \ldots & \ldots & 8 .\end{array}$

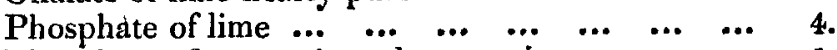

$\begin{array}{llllll}\text { Phosphate of ammonia and magnesia } & \ldots & \ldots & \ldots & 1 .\end{array}$

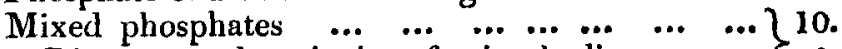
Ditto deposited on foreign bodies ... $\ldots\} 3$.

$\begin{array}{llllllllll}\text { Cystic oxide } & \ldots & \ldots & \ldots & \ldots & \ldots & \ldots & \ldots & \ldots & 2 .\end{array}$

Alternating Calculi.

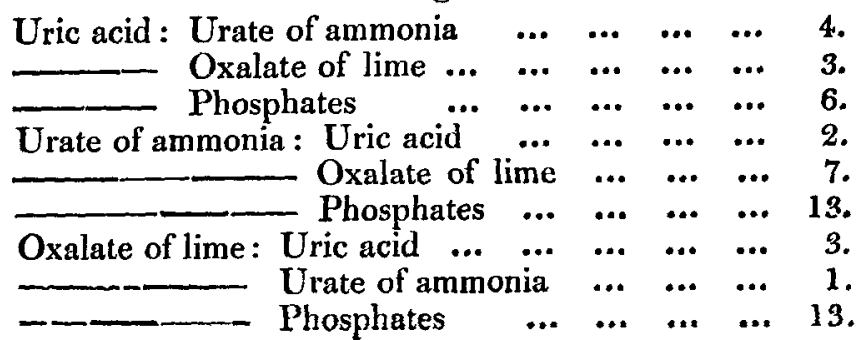




\section{Mr. T. Taylor's Observations on Urinary Calculi}

Uric acid: Urate of ammonia : Phosphates ... 3.

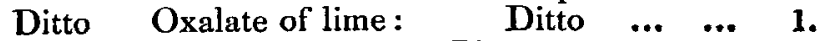

Urate of ammonia: Uric acid : Phosphates ... 1 .

—_ Oxalate of lime: Ditto _.. 13.

\begin{tabular}{|c|c|c|}
\hline & Ditto & Uric acid \\
\hline Oxalate of lime: & Uric acid: & Ditto $\quad \ldots$ \\
\hline
\end{tabular}

Uric Acid.-Of these calculi, the greater number has been taken from adults; the finest specimen, which is remarkably compact and crystalline, was extracted by Mr. Lawrence from the bladder of a man aged 72: some few contain a little urate of ammonia, and in these a minute quantity of oxalate and phosphate of lime may be detected.

Urate of Ammonia.-In no table that has been given by writers on this subject has urate of ammonia been regarded as forming an independent concretion, and its existence as such has been much disputed. This difference in opinion has arisen from the difficulty of separating this salt, in an unexceptionable manner, from the triple phosphate with which it is frequently mixed.

The chief chemical evidence adduced in favour of its presence, is the evolution of ammonia when these calculi are treated with a solution of caustic potash. It has been contended, on the other hand, that the ammonia is derived from the decomposition of the phosphate of ammonia and magnesia, or of urea accidentally present. When the former is the case I am not aware of any method by which this objection can be set aside, for every plan which I have hitherto tried of separating these salts so as to avoid their reaction on each other has failed. There are, however, many calculi in which the presence of urate of ammonia can be satisfactorily shown, and which contain none of the triple phosphate, or which contain it in so small a quantity as to be inadequate to account for the quantity of ammonia combined with the uric acid; and as these calculi possess the same external appearances, and in their general chemical characters correspond exactly with those containing the phosphate of ammonia and magnesia, I think it fair to infer that their composition is similar. Notwithstanding therefore the deservedly high authorities by which the contrary opinion has been maintained, I must fully concur in the observation of Dr. Prout, that all those calculi which present when broken an amorphous and earthy-looking fracture, con- 
sist essentially of urate of ammonia. That the ammonia in these calculi is combined with uric acid may be shown in the following manner. Let a small quantity of boiling water be poured over a few grains of the calculus placed in a small paper filter; the solution will on cooling deposit a copious flocculent white precipitate of urate of ammonia, which from its appearance alone, may be easily distinguished from the scanty crystalline precipitate which takes place when uric acid calculi are similarly treated: should too much water have been added, it will be necessary to evaporate the solution a little before precipitation of the urate of ammonia will take place. Free uric acid is very frequently present in these calculi, and may be observed in the form of minute crystals mixed with the amorphous precipitate of urate of ammonia, or adhering to the sides of the vessel; when however the triple phosphate is present this test is of no value, for the mere affusion of hot water over a mixture of pure uric acid and phosphate of ammonia and magnesia will give rise to the formation of urate of ammonia, and thus vitiate the result. This fact appears to add considerable weight to the opinion of Dr. Prout, that uric acid is seldom or ever deposited in a free state together with the phosphates. There is another distinctive character by which these calculi may always be recognised, viz. their decrepitating on the application of heat: in no well-marked specimen has this property been wanting, and I consider it as perfectly characteristic of the species. To what this peculiarity is owing it is not easy to determine, for pure urate of ammonia does not decrepitate when heated. It has been generally referred to the small quantity of oxalate of lime contained in these calculi; but this is hardly probable, as oxalate of lime calculi undergo combustion silently, and the same property is possessed by those specimens in which the phosphates form the predominating admixture. It may possibly arise from the sudden extrication of ammonia, and its degree of force depend upon the compactness of the body, for in those calculi which from the predominance of the earthy phosphates are porous and friable, this property is considerably impaired or altogether lost. As far as my observation has gone the urate of ammonia in these calculi is never in a state of purity, all of them containing variable quantities of oxalate of lime, the phosphates, uric acid, and in some few instances urate of lime.

The quantity of earthy matter however in the compact varieties is very small, seldom exceeding a few parts per cent. $15 \mathrm{grs}$. of a specimen which was rather disposed to crumble, 


\section{Mr. T. Taylor's Observations on Urinary Calculi}

and in which the characters of urate of ammonia began to pass into those of the phosphates, gave on analysis:

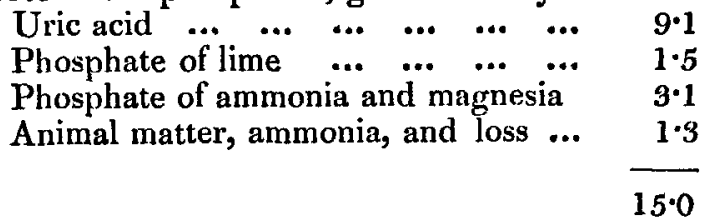

The ash which is left when these calculi are burnt is almost always alkaline and infusible: in three cases only were the phosphates present in such proportions as to render it fusible. By reference to the table it will be seen that urate of ammonia, so far from being rare, as is generally stated, forms in the present collection the most frequent primary deposit; as out of 82 calculi which have been divided, the proportion as to nuclei is as follows: uric acid 18, urate of ammonia 41 , oxalate of lime 23 ; and in those which are homogeneous the proportion of urate of ammonia though less is still very considerable. It has been remarked-by Dr. Prout, that this species of calculus generally occurs in children, and the accuracy of this observation is fully borne out by the histories attached to these calculi; for although unfortunately they are not so perfect as to enable me to institute a strict comparison of the relative frequency of each variety at the different periods of age, yet in the present case by far the greater number are expressly stated to have been taken from persons under puberty.

Phosphate of Lime.-Under this head are arranged some small calculi from the prostate gland, and three large irregular concretions from the kidney; two of these contained carbonate of lime and some urate of ammonia, the latter being apparently in separate layers. In one a small quantity of the phosphate of ammonia and magnesia was likewise present. Whether the phosphate of lime in these calculi was primarily secreted, or merely coated a nucleus of some other substance, is uncertain, as on account of their figure it was not considered advisable to divide them. The other specimen was examined by Dr. Hue, and consisted of phosphate of lime with a large quantity of animal matter.

The term bone earth which is frequently applied to these calculi is faulty, as it conveys the idea that the lime and phosphoric acid are in the same relative proportions as in the earthy matter of bones; whereas it has been shown by Dr. Wollaston that the calculi from the prostate gland contain a much larger proportion of acid, forming what is usually termed the neutral phosphate, or more correctly speaking the diphos- 
phate. From several facts which I have observed, I am, however, convinced that the relative proportions of acid and base in the phospbate of lime surrounding other calculi, whether alone or mixed with the phosphate of ammonia and magnesia, varies considerably: and whether this arises from a mixture of two or more of the already known compounds of lime and phosphoric acid, or whether they are definite compounds of which we have at present no knowledge, I am unable to decide, although I believe the latter may occasionally be the case. In a calculus which consisted of urate of ammonia and oxalate of lime surrounded by the mixed phosphate, was observed among the latter a layer which had an imperfectly fibrous structure and was much harder in texture and more compact than the rest: on digesting a portion of this in dilute acetic acid effervescence took place and some lime was dissolved; the insoluble matter. left had a crystalline appearance, and was found to be phosphate of lime. When dissolved in stronger acid and the solution neutralized by ammonia a gelatinous precipitate fell, which after standing about four and twenty hours was wholly converted into a number of small crystals, having undergone similar changes to freshly precipitated uric acid. If these crystals are left for a few days in the solution from which they have been thrown down, they gradually disappear, and are reconverted into an amorphous precipitate, differing only from the former in not being quite so gelatinous. The nature of the changes which take place $I$ am unable at present to explain, although $I$ find that when the diphosphate of lime (prepared by dropping a solution of phosphate of soda into one of muriate of lime, the latter being in excess, ) is precipitated from its acetic solution, the same appearances present themselves: the conversion is, however, only partial. The calculi which contain this phosphate usually partake more or less of the external characters before mentioned; in some of them it appeared to be mixed with the bone-earth phosphate, properly so called. If it be identical in composition with the diphosphate, which I believe to be the case, the property alluded to is not noticed in any of the chemical works I have consulted. I am informed by Dr. Prout, that he has remarked the same. Only in one instance have $I$ seen the radiated structure noticel by Dr. Wollaston; it formed a thin layer among the mixed phosphates, surrounding a calculus of oxalate of lime.

Phosphate of Magnesia and Ammonia.-This specimen has not been divided; it probably contains a nucleus of uric acid, and should therefore have been arranged among the alternating calculi.

Phil.Mag. S. 3. Vol. 12. No. 76. May 1838. zO 


\subsection{Mr. T. Taylor's Observations on Urinary Calculi}

Mixed Phosphates. - The calculi arranged under this division are composed throughout of the phosphate of lime and phosphate of magnesia and ammonia mixed in variable proportions. Some of these contain thin layers of urate of ammonia, and this salt is frequently present in the fusible calculus.

The number of calculi of this description is rather above the usual average, as the phosphates seldom form the primary deposit.

It is probable that some of these calculi were formed by the decomposition of urine, which from some cause or other could not escape from the bladder; such appears to have been the case in two of these specimens; one having been extracted by Mr. Stanley, from a cyst which communicated with a fistulous passage leading from the bladder to the perinæum; and the other having occurred in a patient in whom, on account of an enlarged prostate gland, lithotomy had been performed above the pubes, and through which opening the urine was subsequently expelled.

Cystic Oxide.-Of these calculi a full description has been given in the Phil. Mag. for April.

Carbonate of Lime.-This salt rarely forms the principal constituent in calculi from the human subject, and no specimen of the kind exists in the museum; it is however very frequently present in small quantities, and generally mixed with the phosphates.

Purpurate of Ammonia.-Of this singular substance it is not easy to obtain decisive chemical evidence, partly on account of the small quantities in which it occurs, and partly on that of the facility with which it undergoes changes by which its colour is destroyed. I believe I am correct, however, in stating that $I$ have detected it in three instances. In one it formed flesh-coloured layers alternating with the phosphates, in the others it merely coated the calculus. In all of them it was mixed with urate of ammonia.

With regard to the alternating calculi the table that has been given expresses nearly all that is worthy of particular notice. It may be observed that in no one instance have the phosphates either pure or in a state of mixture formed the nucleus ; indeed this circumstance is so extremely rare, that it has been laid down as a general law by the highest authority on the subject, "that a decided deposition of the mixed phosphates is not followed by other depositions." There is, however, one specimen in the museum which must be regarded as presenting an exception to this statement.

The calculus in question consists at its centre of urate of 
ammonia containing a little oxalate of lime, around this is oxalate of lime nearly pure, a white layer three eighths of an inch in thickness follows, and is followed by a thin stratum of oxalate of lime of a very dark colour; upon this is deposited crystalline uric acid marked with the irregular concentric lines peculiar to oxalate of lime calculi, although it contains but a mere trace of that substance: the whole was coated by urate of ammonia, uric acid, and oxalate of lime irregularly deposited. As in the museum catalogue the white layer was merely described as fusible, and as Dr. Prout (to whom, with the permission of $\mathrm{Mr}$. Stanley, 1 had the pleasure of showing this specimen,) suggested that it might contain urate of soda, it was carefully examined for that substance, and the result was, that in addition to the mixed phosphates with some carbonate of lime, a small quantity of uric acid and soda was present. The quantity of the latter was, however, very minute; oxalate of lime could not be detected.

It is highly probable that in this case the deposition of the phosphates had been caused by the use of alkaline remedies, and that on the discontinuance of these, the former diathesis had returned. If this were the case it can hardly be considered as a fair exception to the law above mentioned.

By most writers on this subject, a species of calculus bas been noticed, consisting of the different ingredients mixed indiscriminately together, from which circumstance it has been termed mixed or compound. The only specimens which appear to me to deserve this appellation are the mixed phosphates and the less pure varieties of urate of ammonia. As however there is no calculus which is absolutely pure, and it would be exceedingly difficult to decide what proportion of the dissimilar ingredients should constitute a mixed calculus, this class has not been included in the arrangement. I may, however, remark that with the exception of those layers which occasionally intervene between two different deposits, and which, as has been remarked by Dr. Prout, usually consist of a mixture of the old and new layers, only two specimens have come under my notice at all approximating to the so-called mixed calculus, or in which the slightest hesitation occurred in assigning their proper place : of one of these I have given the analysis under the head of urate of ammonia : the other contained a much larger relative proportion of the mixed phosphates and surrounded a nucleus of uric acid, it was therefore arranged among the alternating calculi. Although in the foregoing observations I have endeavoured to confine myself to points of general interest or on which a difference of opinion existed, yet I am afraid they have already extended to too great a length, and I shall therefore no longer intrude 
upon your notice, merely requesting their insertion at your earliest convenience.

I am, Gentlemen, yours, \&c.

New Bridge Street, April 13, 1838. Thomas TaYlor, M.R.C.S.

LXIX. On the Luminosity of the Human Subject after Death, with Remarks and Details of Experiments made with a vierw of determining the nature of the fact. By Mr. Daniel Cooper, A.L.S., Curator to the Botanical Society of Lonilon, \&c., and Mr. Robert Cooper.*

$\mathrm{N}$ the 14th day of February, 1838, the body of William Tomkins, aged 88 , shoemaker by trade, was received at the Webb-street School of Anatomy and Medicine, Borough, having died of age and debility; and on the $3 \mathrm{rd}$ of March that of Robert Boreham, aged 45, was also received with the following history. It appeared that this individual, previous to his death, had been observed in the street in a state of extreme poverty, and was accordingly conveyed by a police officer on duty to the Station House, where, from extreme fatigue and exhaustion, the man died on the 26th of February. Being an unclaimed corpse, the parish authorities (according to the regulations of the Act of Parliament for supplying the Anatomical Schools with subjects for dissection) sent it to Webb-street. Previous to the reception of the latter, nearly the whole of the first subject had been dissected, and the only part which exhibited the luminous property was the left leg, which had been removed, according to custom, at the upper third of the thigh. Not having been informed of this phænomenon until it had been despatched for interment, we had not the opportunity of making experiments with regard to the cause.

We were, however, more fortunate with the latter subject, which presented the same appearance, but in a greater degree. Upon examination it was evident that the man had been a muscular and likewise a hard-working individual, if we might be allowed to judge from the appearance of the skin of the palms of the hands.

The phænomenon was first observed by Mr. J. Appleton, (the Curator to the above establishment, ) on Saturday the 3rd March, upon taking his accustomed round of an evening to every part of the building previous to retiring to rest. $\mathrm{He}$ was greatly surprised at perceiving the extremity before mentioned to be luminous; never having heard or witnessed in the whole course of his experience, commencing in 1812, a similar occurrence.

* Communicated by the Authors : see the Intelligence and Miscellaneous Articles in a future page. 